\title{
HENRY JAMES NO BRASIL (1945-2014) ${ }^{\mathrm{i}}$
}

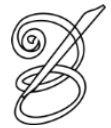 \\ Denise Bottmann ${ }^{\mathrm{ii}}$ \\ Historiadora, tradutora, docente UNICAMP (1983-1998) \\ dbottmann@gmail.com
}

ste levantamento apresenta os textos de Henry James traduzidos e publicados em
livro no Brasil, relacionados em ordem cronológica. Em vários títulos, acrescento a
data das reedições, apenas a título complementar, sem nenhuma pretensão sistemática.

I. O primeiro James

Até onde sei, o primeiro escrito de James a sair em livro no Brasil foi o conto "Four Meetings", "Quatro encontros", em tradução de Vinícius de Moraes. Saiu na coleção "Contos do Mundo", volume 3, Os norte-americanos: antigos e modernos, com organização do próprio Vinícius, pela editora Leitura, em 1945. Foi incluído em Contos norte-americanos pela BUP, em 1963; a Ediouro tem reeditado o volume completo da Leitura, com o título de Contos norte-americanos: os clássicos.

II. Seu segundo texto publicado no Brasil foi o ensaio "Balzac", lançado em 1954 como introdução ao volume XVII da Comédia Humana de Balzac, pela Globo.

\section{O primeiro romance}

Em 1955, temos o primeiro romance de Henry James entre nós, Washington Square, com o título de A Herdeira, em tradução de Ondina Ferreira, na Coleção Saraiva, vol. 82.

IV. Um surtinho de contos

Em 1958, "O romance de uns velhos vestidos" sai em Obras-primas do conto de terror, seleção de Jacob Penteado, sem indicação de tradutor, pela Livraria Martins. 
No mesmo ano e pela mesma editora, temos "Um peregrino apaixonado" na coletânea organizada por Sérgio Milliet, Obras-primas do conto norte-americano, sem nome de tradutor.

Ainda em 1958, sai também "Brooksmith" em Mar de histórias, vol. 3 (Século XIX 2a. Parte), de 1958, em seleção e tradução de Aurélio Buarque de Holanda e Paulo Rónai, pela José Olympio. Reeditado a partir de 1982 pela Nova Fronteira, no volume "Caminhos cruzados” da edição revista e ampliada de Mar de histórias.

\section{A amusette, como dizia H. James}

A seguir, em 1961, vem a menina dos olhos das editoras, The Turn of the Screw, título este que costuma ser vertido ao pé da letra, resultando num abstruso $A$ volta do parafuso ou Outra volta do parafuso ou ainda A outra volta do parafuso. Há editoras que usam o título Os inocentes, na esteira do filme The Innocents, com o célebre roteiro de Truman Capote.

O aparecimento dessa novela entre nós foi tardio: lançada em 1898, só chegou aqui passados mais de sessenta anos. Talvez para compensar o atraso, de lá para cá sucederam-se

246 nada menos que nove traduções diferentes e quatro adaptações. A primeira delas, e de longe a mais conhecida e reeditada até hoje, é a tradução de Brenno Silveira, que adotou o título de Outra volta do parafuso.

Em 1970, a Abril Cultural, em sua coleção "Imortais da Literatura Universal" (reed. em 71, 72, 74, 76), licencia a tradução de Brenno e acrescenta ao volume o conto Lady Barberina, em tradução de Leônidas Gontijo de Carvalho. Em sua reedição de 1980, a Abril acrescenta um "A" ao título, tornando-se A outra volta do parafuso (reed. em 81, 82, 83). Em 1985, a tradução de Brenno Silveira sai pelo Círculo do Livro, com o título inicial (reed. em 90). Em 2002, sai pela Nova Cultural, novamente com Lady Barberina e o "A" no título (reed. em 2003). Em 2010, a Clássicos Abril retoma o título inicial, Outra volta do parafuso.

\section{Retorna a herdeira}

Em 1967, a BUP (Biblioteca Universal Popular, vol. 66) publica A herdeira (Washington Square) em tradução de Berenice Xavier. Essa tradução de Berenice Xavier é licenciada para a Abril Cultural, na coleção "Grandes Romancistas", em 1984. 


\section{Outro conto}

No mesmo ano de 1967, na coletânea 7 novelas clássicas, com tradução de Márcio Cotrim e outros, sai pela Imago/ Lidador o conto "Um episódio internacional".

\section{Volta a amusette}

Infelizmente não sei em que ano foi inicialmente publicada $A$ volta do parafuso em tradução de Olívia Krähenbühl, pela Cultrix, tradução esta que é licenciada em 1969 para a Ediouro (então Tecnoprint), onde se mantém até hoje.

É publicada também pelo Clube do Livro em 1971, reed. 72, surpreendentemente trazendo os devidos créditos de tradução. ${ }^{\text {iii }}$ Em 1979, o Clube do Livro troca o título da obra para Os inocentes, e em 1987 retoma o título inicial adotado pela tradutora.

IX. Um pouco de novidade

Em 1971 sai A roda do tempo, trazendo também "Lady Barberina" e "O mentiroso", em tradução de Leônidas Gontijo de Carvalho, na Coleção Sempreviva, v. 10, da Civilização Brasileira.

$\mathrm{X}$. Começam as adaptações infanto-juvenis da amusette jamesiana

Em 1972, The Turn of the Screw sai com o título de Os inocentes, em adaptação infanto-juvenil de Marques Rebelo, na Coleção "Elefante" da Ediouro.

\section{A versão espírita}

Em 1980, sai mais um Os inocentes, por uma pequena editora de Matão, O Clarim, em tradução de Wallace Leal Rodrigues, com um prefácio expondo sua interpretação kardecista da obra.

XII. Mais um pouco de variedade

Em 1984, finalmente é publicado um terceiro romance de James, Os papéis de Aspern, em tradução de Maria Luiza Penna, na Coleção "Armazém do Tempo" da Global.

Também em 1984, sai outra tradução de Os papéis de Aspern, feita por Álvaro A. Antunes, pela pequena editora Interior, de Além Paraíba. 
XIII. Outro conto

Em 1985, sai A fera na selva, pela Rocco, na Coleção "Novelas Imortais", em tradução de Fernando Sabino.

XIV. Prossegue o James contista

Em 1986, o Clube do Livro lança Os quatro encontros, incluindo o conto de mesmo título e mais "O discípulo" e "O mentiroso", em tradução de Aristides Barbosa (é de se notar que esta tradução segue outra edição de “Four Meetings”, bem diferente da usada por Vinícius de Moraes).

$\mathrm{XV}$. A amusette agora no segmento dos didáticos

Em 1987, a Scipione lança Os inocentes, com o subtítulo em corpo menor de A volta do parafuso, numa adaptação infanto-juvenil por Cláudia Lopes, na Série Reencontro, para compras do governo de livros paradidáticos (reedições anuais ininterruptas, até hoje).

248 XVI. Novidades e repeteco

Em 1991, a Imago lança Daisy Miller / Um incidente internacional, em sua Coleção Lazúli, em tradução de Onédia Célia Pereira de Queiroz.

No mesmo ano, temos a tradução de Margarida Patriota, Pobre herdeira da Washington Square, pela Alhambra, 1991.

XVII. Agora vai

Em 1993, saem cinco contos enfeixados em A morte do leão: histórias de artistas $e$ escritores, pela Companhia das Letras, em tradução de Paulo Henriques Britto. Traz "A morte do leão", "A lição do mestre", "A coisa autêntica", "Greville Fane" e "O desenho no tapete".

XVIII. Até que enfim

Também em 1993, o Círculo do Livro lança Retrato de uma senhora, em tradução de Gilda Stuart. Essa tradução é licenciada em 1995 para a Companhia das Letras, onde permanece até hoje. 
XIX. Variando um pouco

Em 1994, é lançada uma coletânea de contos selecionados e traduzidos por José Paulo Paes, pela Companhia das Letras, enfeixados sob o título de Até o último fantasma: contos fantásticos. Traz "Sir Edmund Orme", "A coisa realmente certa", "Os amigos dos amigos", "O grande e bom lugar" e "A bela esquina".

XX. Mais um romance

Também em 1994, a mesma editora lança Pelos olhos de Maisie, em tradução de Paulo Henriques Britto. Em 2011, essa tradução é publicada numa versão revista pela Penguin-Companhia, em formato de bolso:

XXI. Mais novidades

Ainda em 1994, a Ediouro, em sua coleção Clássicos de Bolso, lança Os europeus, em tradução de Laura Alves.

XXII. Haja herança

Em 1995, sai pela Nova Fronteira uma nova tradução de Washington Square, também com o título de A herdeira, feita por Newton Goldman. Essa tradução de Newton Goldman é licenciada em 1996 para o Círculo do Livro (reed. 97, 99).

XXIII. Começam a se repetir os contos

Ainda em 1995, a Nova Alexandria publica A vida privada e outras histórias, em seleção e tradução de Onédia Célia Pereira de Queiroz (reed. 2001). Contém "A vida privada", "A lição do mestre" e "O desenho no tapete" (uma pena: já dispúnhamos destes dois contos desde 1993).

\section{Alvíssaras}

Continuando em 1995, sai A arte da ficção, excertos de The Art of Novel selecionados por Antonio Paulo Graça e traduzidos por Daniel Piza, pela Imaginário, na Série Olhar Crítico (reed. 1996). Em 2011, essa seleta é reeditada pela Novo Século. 
XXV. Mais alvíssaras

Em 1996, sai pela Sette Letras o estudo Gustave Flaubert, em tradução de Léa Viveiros de Castro, reed. em 2000.

\section{Outra repetição}

Em 1996, reed. 1997, sai mais uma A lição do mestre, agora pela Paz e Terra, Seção Leitura, em tradução de Afonso Teixeira Filho e Rui Costa Pimenta.

XXVII. Boas novas

Em 1997, a Imago publica A Madona do futuro, um dos contos favoritos do próprio autor, em tradução de Arthur Nestrovski.

XXVIII. Viva!

Em 1998, a Ediouro publica As asas da pomba, tradução de Marcos Santarrita daquele portento que é The Wings of the Dove.

XXIX. Variando um pouco

Em 2000, sai uma edição bilíngue The Pupil, O pupilo, em tradução de André Cardoso, na Coleção Biblioteca Alumni, da Imago/ Alumni.

XXX. Em 2001 temos a retradução de “A fera na selva”, em América - Clássicos do conto norte-americano, agora por Celso M. Paciornik, pela Iluminuras.

XXXI. Mais boas novas

Em 2002, finalmente sai The Golden Bowl, A taça de ouro, pela Record, em tradução de Alves Calado, reeditada pela BestBolso em 2009.

\section{Continuam as alvíssaras}

Em 2003, sai pela Globo A arte do romance: antologia de prefácios, em seleção, apresentação e tradução de Marcelo Pen, com oito textos.

No mesmo ano, sai pela Record A selva do amor: Contos clássicos da guerra dos sexos, coletânea organizada por Roberto Muggiati, que traduziu "Diário de um homem de cinquenta". 
Ainda em 2003, temos "O banco da desolação" em A selva do dinheiro: Histórias clássicas do inferno econômico, coletânea com seleção e tradução de Roberto Muggiati, também pela Record.

\section{Outro conto}

Em 2004, sai o conto "A decisão correta" na coletânea Clássicos do sobrenatural, em seleção e tradução de Enid Abreu Dobránszky, pela Iluminuras.

\section{Surpresa}

Em 2004, um surpreendente Viver com sabedoria: mensagens para a busca da felicidade eterna, pela Reader's Digest do Brasil, com mensagens de Kafka, Jane Austen e outros, entre eles Henry James.

\section{Ainda a amusette}

Em 2005, a Companhia das Letras lança Contos de horror do século XIX, onde comparece A volta do parafuso em tradução de Marcelo Pen - que, aliás, lucidamente comenta em seu prefácio que a tradução do título, embora a tenha mantido como tal, é "um grande equívoco" e, "a rigor, não quer dizer nada em português":

\section{Outra vez}

Ainda em 2005, a Landmark publica em edição bilíngue $A$ volta do parafuso, em tradução de Chico Lopes.

\section{Novidades}

Também em 2005, a Planeta lança Um peregrino apaixonado e outras histórias (as outras são "Eugene Pickering" e "O último dos Valérios"), em tradução de Marcelo Pen.

XXXVII. Mais uma adaptação da amusette

Em 2005, a Rideel publica A volta do parafuso na adaptação de Ana Carolina Vieira Rodriguez (reed. 2010).

XXXVIII. Uma terceira fera

Em 2006, sai pela Cosac Naify A fera na selva, em tradução de José Geraldo Couto. 
XXXIX. Mais do mesmo

Ainda em 2006, outra A volta do parafuso, pela editora Martin Claret, em tradução de Luciano Alves Meira (reed. 2007, 2010).

XL. Repeteco e novidade

Em 2007, a L\&PM publica A volta do parafuso (seguido de Daisy Miller), em tradução de Guilherme Braga e Henrique Guerra, respectivamente (reed. 2008, 2010).

No mesmo ano, temos "O altar dos mortos" em Contos de amor do século XIX, com tradução de José Rubens Siqueira, pela Companhia das Letras.

\section{Por fim}

Em 2008, Os espólios de Poynton saem pela Companhia das Letras em tradução de Onédia Célia Pereira de Queiroz:

\section{Por fim!!}

Finalmente sai em 2010 o aguardado Os embaixadores, pela Cosac Naify, em tradução de Marcelo Pen.

\section{Mais uma volta}

Em 2010, a Hedra lança A volta do parafuso em tradução de Marcos Maffei.

XLIV. Tantas voltas...

Em 2011, pela Penguin-Companhia, sai A outra volta do parafuso, em tradução de Paulo Henriques Britto.

\section{Quase espanando}

Em 2011, a Atual, em sua Coleção Três por Três, lança um volume de adaptações infanto-juvenis com o título Três fantasmas, contendo "O capote", de Nicolai Gogol, "A volta do parafuso", de nosso James, e "Alavasto ou Morrer não é bonito", de Wladyr Nader.

XLVI. Ainda em 2001

“A arte da ficção” retorna, agora em tradução de Roberto Acizelo de Souza, na coletânea de sua organização Uma ideia moderna de literatura, pela Argos. 


\section{Variando}

Em 2012, temos Vida de artista, quatro contos sobre pintores (The history of a masterpiece/ The Madonna of the Future/ The Liar/ The Beldonald Holnein - não sei como ficaram os títulos em português), em tradução de Cláudio Figueiredo, pela José Olympio.

XLVII. Mais novidades

Em 2013 a Autêntica publica Horas italianas, em tradução de Júlio Castañon Guimarães.

Em 2014, pela mesma editora, temos “Na gaiola”, em Quatro novelas e um conto, com organização e tradução de Tomaz Tadeu.

É visível que na década de 1990 há entre nós um salutaríssimo boom jamesiano, embora não suficiente, nem de longe, para preencher as grandes e várias lacunas. Onde está, por exemplo, A princesa Casamassima? E Roderick Hudson? E Os bostonianos? Além disso, muito provavelmente há mais coisas publicadas entre nós, mas que não cheguei a localizar.

Seguem-se algumas imagens de capa:

Figura 1. Edição de 1945, com o primeiro texto de James publicado em livro no Brasil, com tradução de Vinícius de Moraes (fotografia de Josélia Aguiar)

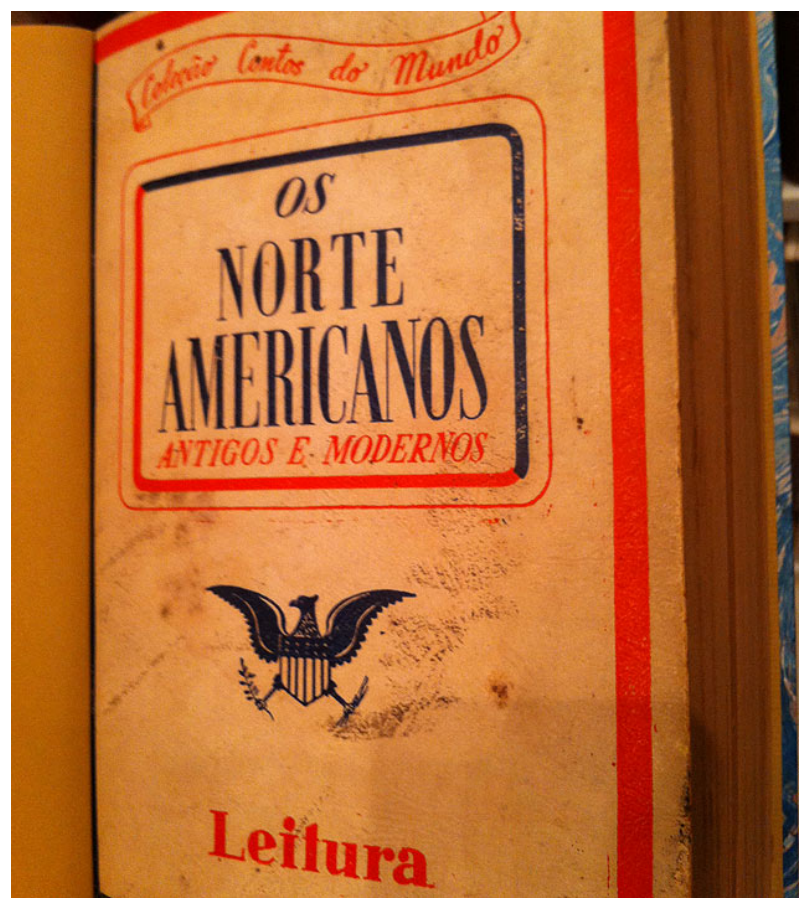


Figura 2. A obra mais traduzida de James no Brasil, aqui em sua primeira tradução, a de Brenno Silveira, lançada em 1961

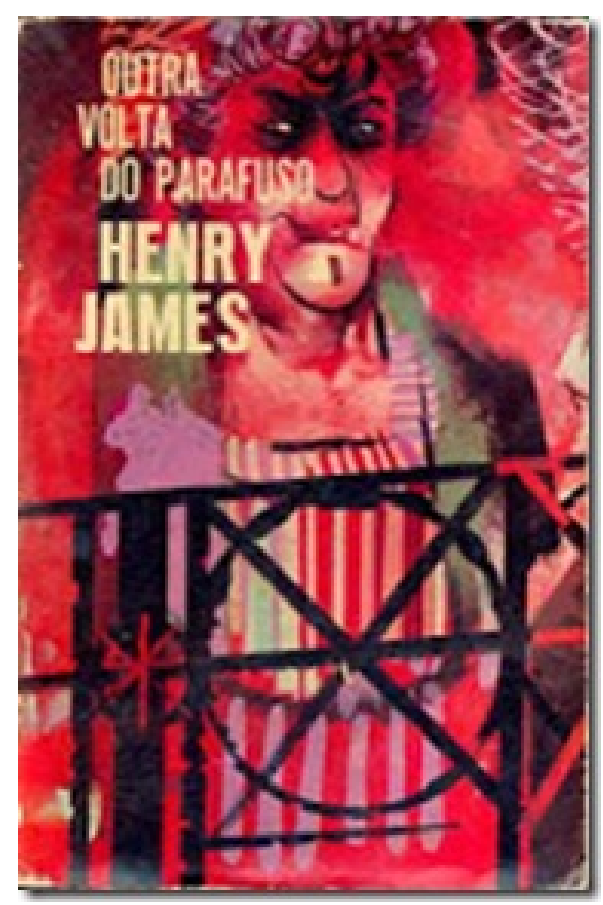

Figura 3. A bela e cuidada tradução de Álvaro A. Antunes, publicada em 1984 pela efemeríssima Interior

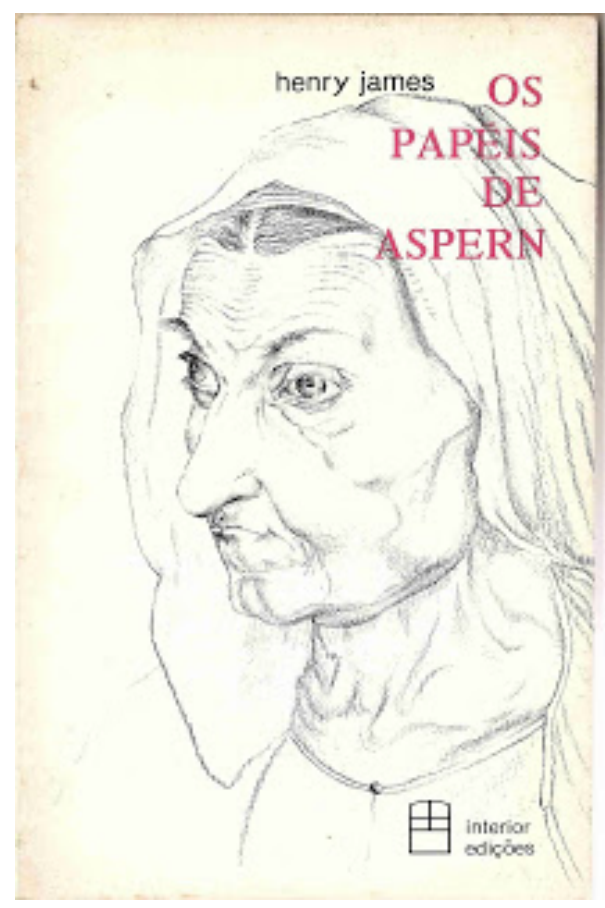




\footnotetext{
i Agradeço a Raquel Sallaberry Brião, Jonas Lopes, Ricardo Duarte e Lucas Cordeiro por várias indicações bibliográficas para este levantamento.

ii Mestre, docente IFCH/UNICAMP (1983-1998), historiadora e tradutora. dbottmann@gmail.com.

iii Digo "surpreendentemente" porque o Clube do Livro era notório por suas "traduções especiais", isto é, traduções portuguesas apenas adaptadas ao português brasileiro, ou antigas e apenas com a grafia atualizada, porém atribuídas a um colaborador constante da editora, José Maria Machado.
}

ACEITO EM: 12 de fevereiro de 2015

RECEBIDO EM: 10 de março de 2015 